\title{
Phosphoproteomic analysis of cell-based resistance to BRAF inhibitor therapy in melanoma
}

\section{OPEN ACCESS}

Edited by:

Petranel Theresa Ferrao, Peter MacCallum Cancer Centre,

Australia

Reviewed by:

Claus Jorgensen,

Cancer Research UK Manchester

Institute, UK

Ben Crossett,

University of Sydney, Australia

*Correspondence:

Mark P. Molloy,

Australian Proteome Analysis Facility,

Department of Chemistry and

Biomolecular Sciences, E8C310,

Research Park Drive, Macquarie

University, Sydney, NSW 2109,

Australia

mmolloy@proteome.org.au

Specialty section:

This article was submitted to Molecular and Cellular Oncology, a section of the journal Frontiers in

Oncology

Received: 05 February 2015 Accepted: 07 April 2015

Published: 15 May 2015

Citation:

Parker R, Vella LJ, Xavier D, Amirkhani A, Parker J, Cebon J and Molloy MP

(2015) Phosphoproteomic analysis of cell-based resistance to BRAF inhibitor therapy in melanoma.

Front. Oncol. 5:95. doi: 10.3389/fonc.2015.00095

\section{Robert Parker ${ }^{1}$, Laura J. Vella ${ }^{2}$, Dylan Xavier ${ }^{1}$, Ardeshir Amirkhani ${ }^{1}$, Jimmy Parker ${ }^{3}$, Jonathan Cebon ${ }^{2}$ and Mark P. Molloy ${ }^{1 *}$}

${ }^{1}$ Australian Proteome Analysis Facility, Department of Chemistry and Biomolecular Sciences, Macquarie University, Sydney, NSW, Australia, ${ }^{2}$ Cancer Immunology Group, Olivia Newton-John Cancer Research Institute, Ludwig Institute for Cancer Research, School of Cancer Medicine, La Trobe University, Heidelberg, VIC, Australia, ${ }^{3}$ NHS Trust Southport and Ormskirk General Hospital, Ormskirk, UK

The treatment of melanoma by targeted inhibition of the mutated kinase BRAF with small molecules only temporarily suppresses metastatic disease. In the face of chemical inhibition tumor plasticity, both innate and adaptive, promotes survival through the biochemical and genetic reconfiguration of cellular pathways that can engage proliferative and migratory systems. To investigate this process, high-resolution mass spectrometry was used to characterize the phosphoproteome of this transition in vitro. A simple and accurate, label-free quantitative method was used to localize and quantitate thousands of phosphorylation events. We also correlated changes in the phosphoproteome with the proteome to more accurately determine changes in the activity of regulatory kinases determined by kinase landscape profiling. The abundance of phosphopeptides with sites that function in cytoskeletal regulation, GTP/GDP exchange, protein kinase C, IGF signaling, and melanosome maturation were highly divergent after transition to a drug resistant phenotype.

Keywords: phosphoproteomics, BRAF, drug resistance, vemurafenib, kinases, label-free quantitation, mass spectrometry

\section{Introduction}

In melanoma, coding mutations in the mitogen-activated kinase pathway (MAPK) (e.g., BRAF and RAS) are common and contribute to disease severity (1). In cutaneous melanoma, BRAF is mutated in $\sim 70 \%$ of cases and correlates with poorer prognosis and aggressive disease $(2,3)$. The mutant BRAF protein is a hyperactive serine/threonine-protein kinase that directs signaling through MEK1/2 to phosphorylate the MAPK ERK1/2 and drive cell proliferation and tumor growth. In recent years, a high-therapeutic value has been attained by targeted inhibition of the mutated BRAF protein with selective inhibitors (e.g., vemurafenib and dabrafenib) (4-6). Vemurafenib and dabrafenib effectively reduce signaling through the MAPK pathway, resulting in disease regression $(\sim 85 \%)$ and progression free survival for $\sim 5-6$ months [reviewed in Ref. (7)], after which almost all treated patients develop drug resistant, progressive disease (5).

Several mechanisms for intrinsic and acquired resistance have been detected in vivo and in vitro and this has been extensively reviewed (7-9). Relapses in melanoma involve mechanisms that reprogram signaling pathways to bypass inhibition and reactivate the ERK1/2 signaling hub (10). For example, the up-regulation of receptor tyrosine kinases (RTKs), platelet derived growth factor (PDGF), epidermal growth factor receptor (EGFR), and insulin-like growth factor 1 receptor 
(IGF-1R) can drive cell survival signals through the PI3K/AKT pathway (11-13). Alternative pathways that reactivate ERK during targeted therapy utilize the multimeric properties of RAF signaling complexes and also occur in BRAF wild-type cells. BRAF inhibitors have been shown to drive the formation of alternative RAF dimers able to phosphorylate MEK and induce ERK signaling (14-17). In drug resistant patients, up-regulation and splicing of MAPK signaling components [CRAF, BRAF, or the MAP3K8 $(\mathrm{COT})]$ provide alternative mechanisms for the reactivation of ERK1/2 signaling (18-20). In response to the microenvironment, phenotypic switching can also occur based upon intrinsic tumor heterogeneity and lead to resistance to therapy (21). For example, paracrine signaling from stromal cells that secrete hepatocyte growth factor (HGF) reestablish the MAPK pathway in BRAF mutated cells by activating the RTK MET (22). Independent of the MAPK pathway, low expression of the melanocyte transcriptional network driver microphthalmia-associated transcription factor (MITF) associates with drug resistance and a more invasive, less proliferative phenotype $(23,24)$. This and the fact that MAPK inhibitors can themselves drive an invasive phenotype (25) indicate that inter-tumor plasticity allows melanoma to evade complete growth arrest in the face of MAPK inhibition.

The discovery of these mechanisms and others [reviewed in Ref. (8)] has established opportunities for novel melanoma treatment. The design of more effective co-inhibitory-based therapies could represent an improved strategy to prevent the acquired resistant phenotypes currently found in the clinic. In most cases, combination therapies in which BRAF inhibition is paired with inhibitors of the well establish mediators of resistance (PI3K, MEK, HGF, and IGF-R1) is showing promise $(12,26,27)$. Because kinases (ERK1/2, IGF-R1, MEK, PI3K) provide key signaling hubs that orchestrate biochemical processes in drug resistant melanoma, characterizing their global activity profiles will aid the design of novel therapies. Kinase activity can be mapped by measuring the abundance of substrates using phosphoproteomic methods that combine phosphopeptide enrichment with highresolution mass spectrometry (28). A quantitative phospho-site (P-site) analysis has the potential to provide a direct readout of kinase activity, elucidate novel mechanisms driving resistance, and guide the selection of therapies for validation in cell and animal models $(29,30)$. Previously, Old et al. reported $\sim 90$ Psites that were regulated in a melanoma cell line in response to short-term MKK1/2 inhibition and Girotti et al. screened the phosphoproteome of A375 cells in a model for in vitro acquired drug resistance $(31,32)$. Both studies identify changes in the intensity of $\mathrm{P}$-sites in signaling and cytoskeletal regulators and support the co-inhibition of specific kinase signaling (EGFR-SRC and SFK-STAT3) to provide therapeutic efficacy in drug resistance (32). To add to this work, we have developed and applied a simple and reproducible label-free quantitative phosphoproteomic procedure and analyzed an in vitro model of acquired drug resistance in melanoma cell line LM-MEL-28. The abundance of 2230 P-sites was measured by high-resolution mass spectrometry and correlated with the abundance of 3556 unmodified proteins to provide a more accurate determination of kinase activity. Kinase-substrate databases (Phosphosite.org, cell signaling) and motif analysis (NetworKIN) of the flanking linear amino acid sequences predicted several regulatory kinases that are most likely to be responsible for differential phosphorylation detected during long-term exposure to BRAF inhibition in LM-MEL-28. Key regulatory sites that control actin and microtubule-based cytoskeleton and cellular GTP/GDP ratio exhibited large changes in phosphorylation. Phosphorylation of the melanosome G-protein coupled receptor (GPCR) OA1 (GP143) indicated a direct role for the melanocyte maturation pathway. While sites of phosphorylation of the insulin receptor substrate IRS-2 and IGFR2 indicated novel points of regulation in the IGF-1R pathway previously identified to mediate drug resistance in melanoma.

\section{Materials and Methods}

\section{Cell Culture and Protein Preparation}

The melanoma cell line LM-MEL-28 was selected from the Ludwig Institute for Cancer Research Melbourne Melanoma Cell Line Panel (33). LM-MEL-28 was cultured in RPMI 1640 medium supplemented with $10 \%(\mathrm{v} / \mathrm{v})$ bovine serum (Life Technologies) at $37^{\circ} \mathrm{C}$ in a humidified atmosphere of $5 \% \mathrm{CO}_{2}$. Cells were treated with PLX4720 (Selleck Chemicals) for a 1-month period in $5 \mu \mathrm{M}$ PLX4720 to generate a drug resistant line referred to LM-MEL28R1. Cells were tested for authenticity by short tandem repeat profiling according to the ANSI/ATCC ASN-0002-2011 standards. For phosphoproteomic analysis, six biological replicates were generated by sub-culture and cells were grown to $80-90 \%$ confluence with the LM-MEL-28-R1 continuously cultured in the presence of $5 \mu \mathrm{M}$ PLX4720 and LM-MEL-28 in the presence of vehicle. Cells were washed three times in PBS and harvested by gentle enzyme-based release (TrypLE), pooled and centrifuged at $400 \times g$, cell pellets frozen on dry ice and stored at $-70^{\circ} \mathrm{C}$. Cells were lysed by boiling for $5 \mathrm{~min}$ in $1 \%(\mathrm{w} / \mathrm{v})$ sodium deoxycholate (Sigma), $50 \mathrm{mM}$ triethylammonium bicarbonate (TEAB) (Sigma), and $1 \mathrm{mM} \mathrm{MgCl} 2$ (Sigma). Lysates were cooled to $4^{\circ} \mathrm{C}$, sonicated to complete lysis, and DNA was digested by incubation with benzonase (Sigma) (10,000 units). Lysate were centrifuged at $20,000 \times g$ for $10 \mathrm{~min}$ and protein amounts determined by the micro-BCA assay (Pierce). Samples were stored at $-80^{\circ} \mathrm{C}$. Mutational testing was performed by MelCarta assay and all cell lines were tested for mycoplasma and appropriate consent from all patients had been obtained.

\section{Protein Digestion and Phosphopeptide Enrichment}

Five hundred milligrams of total protein lysate were reduced with $5 \mathrm{mM}$ DTT (Sigma) for $30 \mathrm{~min}$ at $60^{\circ} \mathrm{C}$ and alkylated with $10 \mathrm{mM}$ of iodoacetamide (Sigma) in the dark at room temperature for $30 \mathrm{~min}$. Trypsin (Promega) was added at ratio of 1:50 ratio for $18 \mathrm{~h}$ at $37^{\circ} \mathrm{C}$. Samples were adjusted to $1 \%(\mathrm{v} / \mathrm{v})$ trifluoroacetic acid (TFA) (Sigma), $80 \mathrm{mg} / \mathrm{ml}$ glycolic acid (Sigma), and the precipitated deoxycholate was removed by centrifugation. Five milligrams of $\mathrm{TiO}_{2}$ beads (Titanisphere, $10 \mu \mathrm{m}$ ) were washed once in $0.1 \%(\mathrm{v} / \mathrm{v})$ TFA, $70 \%(\mathrm{v} / \mathrm{v})$ acetonitrile $(\mathrm{ACN})$, and $80 \mathrm{mg} / \mathrm{ml}$ glycolic acid, added directly to the sample and incubated with shaking for $1 \mathrm{~h}$. A C8 stage-tip was prepared and washed with methanol (Sigma), then $0.1 \%(\mathrm{v} / \mathrm{v})$ TFA, 70\% (v/v) ACN, and $80 \mathrm{mg} / \mathrm{ml}$ glycolic acid $(40 \mu \mathrm{l}) . \mathrm{TiO}_{2}$ beads were added to the 
C8 stage-tip and tips were centrifuged $1000 \times g$ until all liquid was dispensed. Beads were washed on tip with $300 \mu \mathrm{l}$ of $0.1 \%$ TFA, 70\% ACN, $80 \mathrm{mg} / \mathrm{ml}$ glycolic acid $(300 \mu \mathrm{l})$ twice then thrice with $0.1 \%(\mathrm{v} / \mathrm{v})$ TFA and $70 \%(\mathrm{v} / \mathrm{v})$ ACN. Phosphopeptides were eluted from $\mathrm{TiO}_{2}$ tip with consecutive $100 \mu$ ladditions of $1 \%(\mathrm{v} / \mathrm{v})$ ammonia (Sigma) with 0, 30, and 50\% (v/v) ACN. Samples were immediately dried and resuspended in $1 \%(\mathrm{v} / \mathrm{v})$ TFA and $5 \%(\mathrm{v} / \mathrm{v})$ ACN for LC-MS/MS.

\section{Isobaric Labeling by Reductive Dimethylation and Peptide Separation}

Proteolytic digestion of $100 \mu \mathrm{g}$ total protein was carried out as described above and samples were labeled by reductive dimethylation using formaldehyde isotopologues (34) with slight modifications (35). After labeling, each sample was pooled and $40 \mu \mathrm{g}$ separated into six fractions using $\mathrm{pH}$-based strong anion exchange (SAX) STAGE tips (36) described in Ref. (37).

\section{Mass Spectrometry (LC-MS/MS)}

Samples were loaded onto a self-packed $100 \mu \mathrm{m} \times 3.5 \mathrm{~cm}$ reversed phase peptide trap (Solid core $\mathrm{Halo}^{\circledR} 2.7 \mu \mathrm{m} 160 \AA$ ES-C18, Advanced Materials Technology) and desalted for $10 \mathrm{~min}$ with buffer A $[0.1 \%(\mathrm{v} / \mathrm{v})$ formic acid], peptide separation was carried out using a self-packed $75 \mu \mathrm{m} \times 10 \mathrm{~cm}$ (Solid core Halo ${ }^{\circledR} 2.7 \mu \mathrm{m}$ $160 \AA$ Å $\mathrm{E}-\mathrm{C} 18$, Advanced Materials Technology) column. A buffer B [100\% (v/v) ACN, 0.1\% (v/v) formic acid] gradient (5-40\% in $120 \mathrm{~min}$ ) was used to elute peptides. Phosphopeptides were ionized by electrospray ionization and data-dependent MS/MS acquisition carried out using a Q-Exactive consisting of 1 full MS1 $(R=70 \mathrm{~K})$ scan acquisition from 350 to $1500 \mathrm{~m} / z$, and $10 \mathrm{HCD}$ type MS2 scans $(R=15 \mathrm{~K})$. Dimethylated peptides were analyzed on an Orbitrap Elite (Thermo Fisher Scientific) consisting of 1 full $\mathrm{MS}^{1}(R=120 \mathrm{~K})$ scan acquired from 350 to $1500 \mathrm{~m} / z$, and 10 CID type $\mathrm{MS}^{2}$ scans. On both instruments, monoisotopic precursor selection, charge state screening, and dynamic exclusion were enabled, charge states of $+1,>4$, and unassigned charge states were not subjected to $\mathrm{MS}^{2}$ fragmentation. Raw mass spectra were identified using Maxquant 1.3 using a 1\% peptide and protein FDR. Searches were conducted against the uniprot complete proteome reference database downloaded on June 06, 2014. The database was supplemented with common contaminants often found in cell culture and proteomics experiments these were later removed. Searches specified for tryptic peptides with four missed cleavages, $7 \mathrm{ppm}$ precursor ion mass tolerance, $0.05 \mathrm{Da}$ fragment ion mass tolerance, fixed modifications of carbamidomethylation $(\mathrm{C})$, and variable modification of oxidation $(\mathrm{M})$, acetylation $(\mathrm{N}$ term, protein), and phosphorylation (STY). For phosphopeptides, quantitation was performed using peptide intensity for modified (STY) P-sites and for proteins using the protein intensity ratio from the protein groups detected in the dimethylated data-set generated by Maxquant (38). Statistical analysis was carried out using Perseus 1.5 .0 (39). Intensities were pre-processed by $\log _{2}$ transformation and checked for normality. To identify differentially expressed peptides, the Student's $t$-test were applied to compare groups, $P$ values were filtered for the effect of multiple hypothesis testing using the FDR method $(<5 \%)$. The mass spectrometry proteomics data have been deposited to the ProteomeXchange
Consortium (40) via the PRIDE partner repository with the dataset identifier PXD002079.

\section{Phosphosite Localization and Kinase Assignment}

To localize modifications search results were processed using Maxquant that generates a score and probability function to assign confidence to amino acid modification location based on available peak depth present in MS/MS spectra. Upstream kinases were putatively assigned using the NetworKIN algorithm (41) and Phosphosite database (42).

\section{Viability Assays}

Cell lines were seeded in 96-well plates at 5000 cells/well in triplicate for each drug treatment and time point. After $2 \mathrm{~h}$, cells were treated with dilutions $5 \mu \mathrm{M}$ for vemurafenib (PLX4072) alone or in combination with 1.25 or $2.5 \mu \mathrm{M}$ of the CK2 inhibitor (CX4945). After $72 \mathrm{~h}$, cell viability for each cell line was assessed by Presto Blue Assay (Life Technologies).

\section{Results}

\section{Phosphoproteome Analysis of In vitro Drug Resistance}

Figure 1A outlines the methodology taken to investigate the phosphoproteome of drug-exposed melanoma cells. To model drug resistance, a $B R A F(V 600 E)$ mutant cell line (LM-MEL-28) was cultured in media containing $5 \mu \mathrm{M}$ of the selective BRAF inhibitor PLX-4720 for 1 month to generate the stable cell line, LM-MEL28R. The resistant line LM-MEL-28R was threefold less sensitive to the growth inhibitory effects of PLX4720 than the parental line LM-MEL-28 as shown in a viability assay (Figure 1B). For phosphoproteomic and proteomic analysis, protein extracts were generated, digested with trypsin, and then phosphopeptides were enriched by micro-column based $\mathrm{TiO}_{2}$ chromatography analyzed by LC-MS and total peptides labeled by reductive dimethylation using light and heavy isotopes, mixed, separated by SAX chromatography and analyzed by LC-MS; all steps were performed in triplicate. LC-MS identified 3162 unique phosphopeptides (S,T,Y) sequences, mapping to 1164 distinct protein groups and 16,713 none-phosphorylated peptide spectral matches mapping to 3556 protein groups at a FDR of 1\% using Maxquant; 836 phosphoproteins $(72 \%)$ had dual $\mathrm{P}$-site and protein quant estimates providing added confidence in this dataset for detecting changes in phosphorylation occupancy (Figure 1C; Tables S1-S3 in Supplementary Material). The intensity of all phosphopeptides within replicates exhibited a strong positive correlation and low variance $\left(R^{2}\right.$ of 0.75-0.84 and CV 27.26-28.28\%). Using a probability function, $76 \%$ (2395 of 3162) $\mathrm{p}[\mathrm{S}], \mathrm{p}[\mathrm{T}], \mathrm{p}[\mathrm{Y}]$ sites could be localized with high confidence $(>75 \%)$ by MS/MS spectra (Figure 1D; Table S3 in Supplementary Material). The intensity of all peptides containing P-sites was used to compare cell populations initially, while Class $1(>75 \%)$ was used for assigning kinase-substrate relationships.

\section{Phosphorylation of the MAPK1 Pathway}

Because the MAPK1 pathway is often at the center of acquired drug resistance to $\mathrm{BRAFi}$, we first examined the relative abundance of $\mathrm{P}$-sites in MAPK1, RB1, and CDK1/2, which can provide 
A

LM-MEL-28 (BRAFV600E)

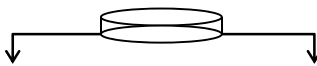

Media + DMSO Media + 5 $\mu$ M PLX4720

\ 1 month

LM-MEL-28

LM-MEL-28 R
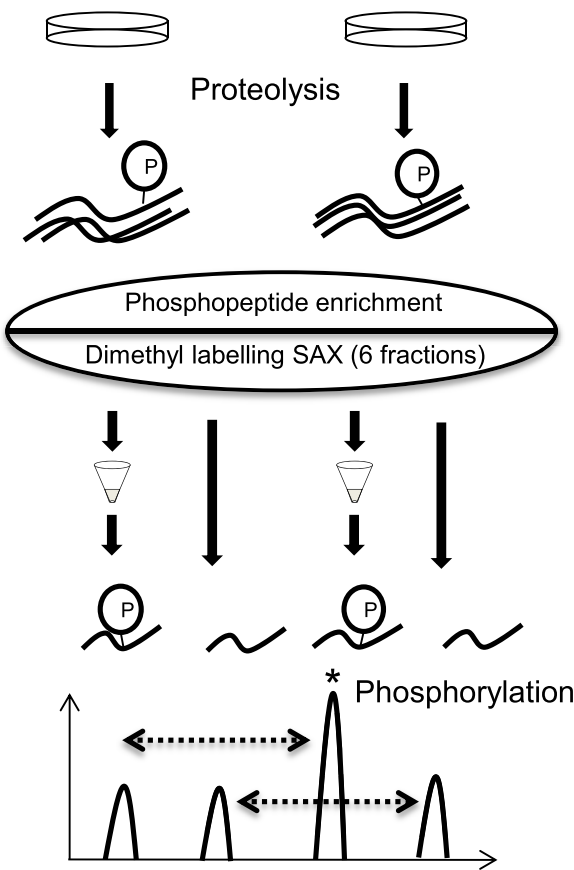

Quantitation by LC-MS \& Maxquant
B
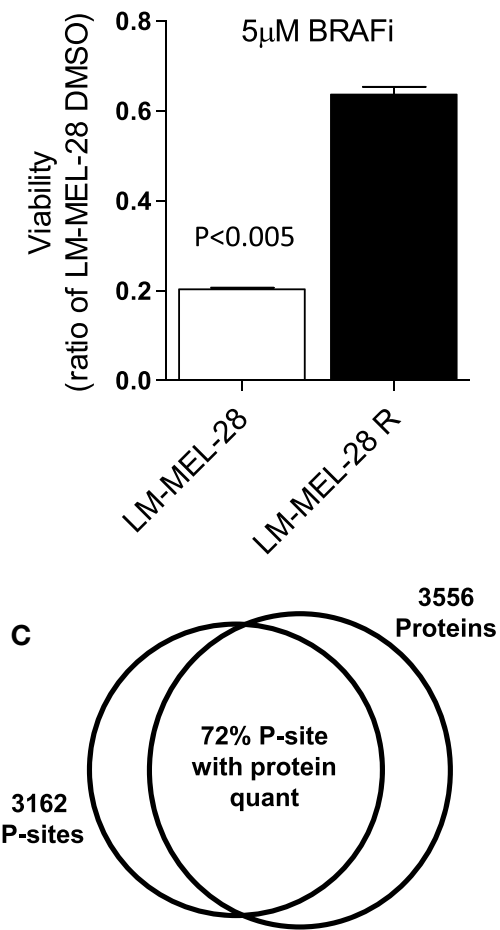

D

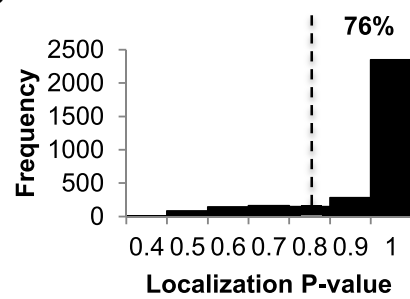

FIGURE 1 | Phosphoproteomic analysis of in vitro drug resistance in melanoma cells. (A) The melanoma cell line LM-MEL-28 BRAF(V600E) was exposed to BRAF inhibitor PLX4072 for 30 days to generate LM-MEL28R cell population. Proteins were extracted, digested, and $\pm \mathrm{TiO}_{2}$ enrichment (for phosphopeptides) or labeled by reductive dimethylation, separated by tip-based strong anion exchange (SAX) chromatography, and analyzed by LC-MS and
Maxqaunt. (B) The viability of LM-MEL-28R and LM-MEL-28 cells when grown in BRAFi was compared after 3 days (error bars are SD). (C) Venn diagram giving the number of P-sites and proteins identified by LC-MS, overlap is calculated where quantitation for P-sites and protein has been determined. (D) Histogram of probability values obtained from Maxquant for P-site localization accuracy, dotted line indicates the $>0.75$ cut-off used for kinase enrichment analysis. a measure of MAPK1 signaling (Figures 2A-C). Regulatory Psites [MAPK1 (T185), RB1 (T821)] and the inhibitory site in CDK1/2 (T/14Y15) were quantified and increased in abundance in LM-MEL-28-R, indicating reactivation/modulation of MAPK1 signaling had taken place in LM-MEL-28R despite continued BRAFi (Figures 2A-C). LC-MS data also provided a site-specific quantitative measure of protein phosphorylation for MAPK1 and $\mathrm{RB} 1$ and can thus indicate the activity of the regulatory kinases. To demonstrate this further, we selected the heavily phosphorylated protein, sequestosome-1 (SQSTM1), a known substrate of CDK1 (S269, S272) and demonstrate divergent site-specific protein phosphorylation is detectable. P-site intensity decreased at sites T269, S272 and increased at site S361 providing a snap shot of the activity of multiple kinase and/or phosphatases that target this protein (Figure 2D).

\section{Proteome of Drug Resistance}

To more accurately determine change in phosphorylation after BRAF drug resistance the proteome of LM-MEL-28 and LMMEL-28R1 cell populations was compared using isotope coded quantitative proteomics and LC-MS (Table S3 in Supplementary Material). Analysis of these data alone indicated widespread regulation of protein biosynthesis occurs during the development of resistance to BRAFi. Using a twofold cut-off, the majority of proteins were found down-regulated (317) and fewer (151) upregulated. 1-D gene set enrichment analysis using the $\log _{2}$ ratio and the Kyoto Encyclopedia of Genes and Genomes (KEGG, http: //www.genome.jp/kegg/) database reflects this and is reported in Table 1 and Table S4 in Supplementary Material). Down-regulated processes indicate major reprograming of metabolic pathways for amino acid metabolism and energy transducing systems (TCA 

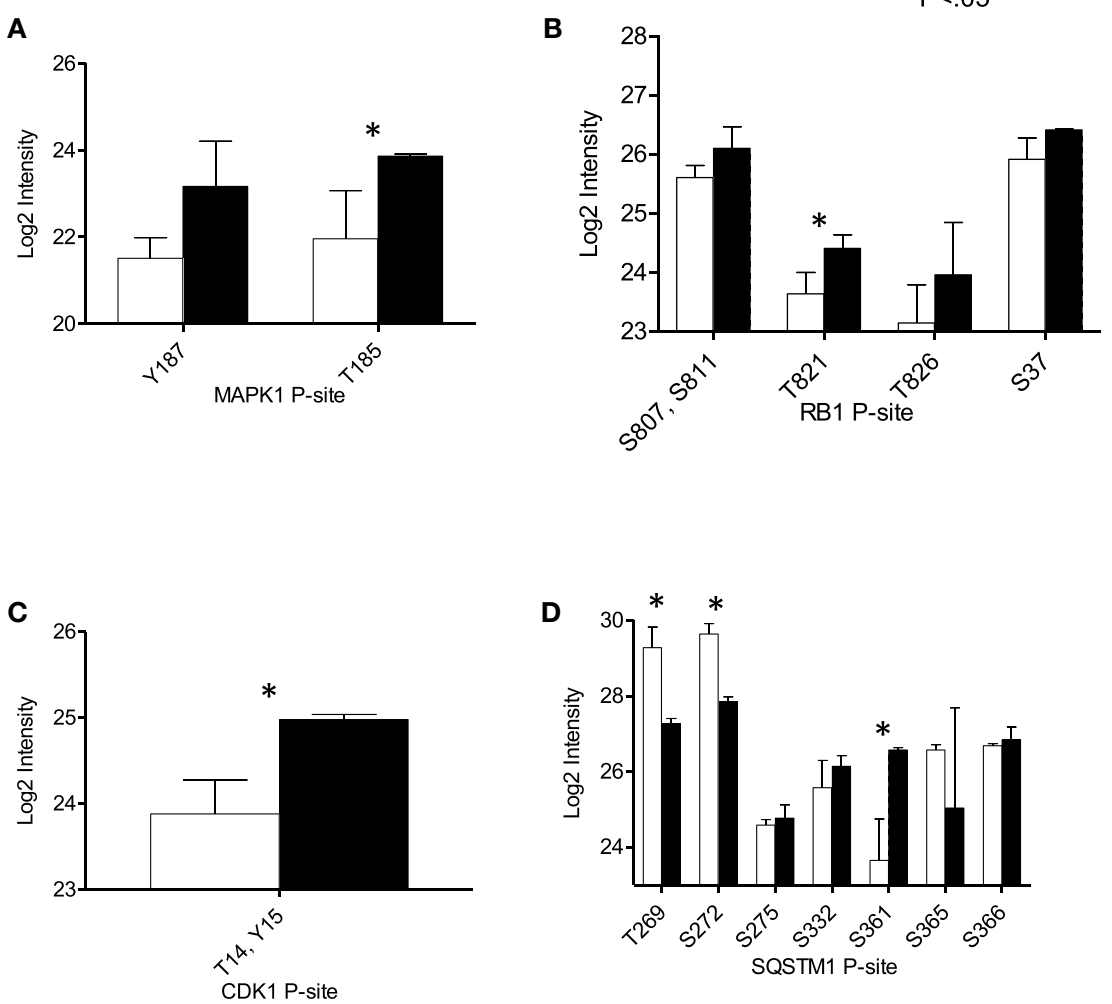

LM-MEL-28

LM-MEL-28 R

FIGURE 2 | Phospho-site analysis of MAP kinase pathway output. (A-D) The $\log _{2}$ intensity of key P-sites from proteins that function in and downstream of the MAPK01 (ERK1/2) pathway signaling are plotted and analyzed using a Student's $t$-test (error bars are SD).

and Glycolysis). Up-regulated processes indicate changes in processes controlling DNA metabolism and the cell cycle.

\section{Phosphorylation Dynamics in Drug Resistance}

With estimates of both P-site and protein effect for drug sensitive and resistant populations of LM-MEL-28, we subtracted the protein effect to determine more accurately changes in the rate of phosphorylation at significant sites. Protein quantitative estimates for 2895 sites $(\sim 72 \%)$ were available and using the following equation (Phospho rate $=\log _{2}$ Phospho $-\log _{2}$ Protein) specific post-translational activity (kinase or phosphatase) was inferred. Figure 3 is an $x / y$ scatter plot of the significant P-sites $(n=148$, Student's $t$-test FDR corrected $P<0.05)$ where $x$ is $\log _{2} \mathrm{P}$-site ratio $(\mathrm{R} 1 / \mathrm{S} 1)$ and $y$ is $\log _{2}$ protein ratio $(\mathrm{R} 1 / \mathrm{S} 1)$. Data were well correlated indicating a large effect of protein abundance on P-site abundance (Pearson's $\left.R^{2}=0.6, P<0.0001\right)$ (Figure 3A). Fortyseven accurately localized $(P<0.75)$ P-sites were differentially regulated by a minimum of twofold after protein abundance was subtracted, and these were selected for kinome analysis using Phosphosite.org and NetworKIN databases $(41,42)$ (Table 2). Seventeen sites originated from singly phosphorylated peptides, 30 sites were from 15 doubly phosphorylated peptides, of which 5 had a second site where the P-site localization was ambiguous (Class 2) (Table S5 in Supplementary Material). All accurately localized sites (Class 1) were used for further analysis, and it was accepted that for sites originating from the same peptide the quantitative value would amount to the sum of regulation at each site.

\section{Kinase Enrichment Analysis}

Using the phosphosite.org and NetworKIN databases, regulatory kinases for 29/46 P-sites could be assigned and are reported in Table 2 and Tables S3 and S5 in Supplementary Material. Of the 46 P-sites, 11 were in key cytoskeletal regulators and kinase predictions were available for 7 of these sites. For example, myosin regulatory light chain, MLC12A/B/9 (T18 and S19) destrin/cofilin (S3) predicts the activity of ROCK1 and LIMK1/2 protein kinases (Figure 3B). P-sites in three distinct guanidine exchange factors (GEF's 11, 40, and 1) were also regulated by phosphorylation and S35 in GEF40 is putative substrate for the p21associated kinase PAK4 (Figure 3C; Table 2). Phosphorylation of two microtubule-associated proteins (MAPs) increased at six sites (Figure 3D). Here, sites S2019, S2022 predicted the activity of CK1A on MAP1A and S1793, S1797 are putative substrates for GSK3 $\beta$ on MAP1B. Other sites of note for which kinase-substrate predictions were determined included two MAPK1 substrates TPR (S2155) and PPP2R2A (S692). Sites in the key signaling molecules insulin receptor substrate 1 (IRS1, S736), the insulinlike growth factor 2 receptor/cation-independent mannose-6phosphate receptor (IGF2R/CI-MPR, S2484), and protein kinase 
TABLE 1 | 1-D gene enrichment analysis

\begin{tabular}{lccc}
\hline KEGG pathway name & Proteins $^{\mathbf{a}}$ & Median $^{\mathbf{b}}$ & $\begin{array}{c}\text { Benj. } \\
\text { Hoch. FDR }\end{array}$ \\
\hline Mismatch repair & 14 & 0.50 & $3.4 \mathrm{E}-03$ \\
DNA replication & 24 & 0.34 & $1.3 \mathrm{E}-04$ \\
Nucleotide excision repair & 21 & 0.26 & $4.6 \mathrm{E}-04$ \\
Cell cycle & 40 & 0.22 & $3.5 \mathrm{E}-04$ \\
Huntington's disease & 97 & -0.37 & $3.3 \mathrm{E}-03$ \\
Oxidative phosphorylation & 73 & -0.40 & $7.2 \mathrm{E}-04$ \\
Alzheimer's disease & 87 & -0.41 & $3.3 \mathrm{E}-03$ \\
Parkinson's disease & 76 & -0.41 & $3.0 \mathrm{E}-04$ \\
Glycolysis/gluconeogenesis & 34 & -0.48 & $4.6 \mathrm{E}-03$ \\
Ribosome & 72 & -0.52 & $1.2 \mathrm{E}-08$ \\
Cardiac muscle contraction & 25 & -0.55 & $6.6 \mathrm{E}-04$ \\
Peroxisome & 30 & -0.59 & $2.9 \mathrm{E}-03$ \\
Aminoacyl-tRNA biosynthesis & 30 & -0.60 & $3.5 \mathrm{E}-04$ \\
Fatty acid metabolism & 24 & -0.60 & $1.6 \mathrm{E}-03$ \\
Citrate cycle (TCA cycle) & 27 & -0.61 & $2.2 \mathrm{E}-03$ \\
Valine, leucine, and isoleucine & 26 & -0.62 & $4.1 \mathrm{E}-04$ \\
degradation & & & \\
Pyruvate metabolism & 27 & -0.63 & $1.4 \mathrm{E}-03$ \\
PPAR signaling pathway & & -0.67 & $2.6 \mathrm{E}-03$ \\
Tryptophan metabolism & & $3.3 \mathrm{E}-04$ \\
& & & \\
\hline
\end{tabular}

${ }^{a}$ Number of proteins annotated with the KEGG pathway.

${ }^{b}$ Median $\log _{2}$ fold change for proteins annotated within the KEGG pathway.

$\mathrm{C}$ (PKC, S497) indicated activity of GSK3 $\alpha / \beta, \mathrm{CK} 2 \mathrm{~A}$, and PDHK1, respectively. Nestin (S680) and sequestosome-1 (T269, S272) decreased in phosphorylation and are predicted to be substrates of CDK1, consistent with the increase in inhibitory phosphorylation of CDK1 (Y15/T14) measured. Finally, Casein kinase 2 alpha (CK2A) was predicted to regulate six sites, four of which increased in abundance for proteins that function in core processes of DNA replication and damage responses [MCM3 (S711, S672) and HERC2 S2928] and protein translation (RPLP1/2, S104/105) (Table 2).

\section{Meta-Analysis}

Recently, Girotti et al. identified major regulation of phosphoproteins involved in cytoskeletal and cell invasion gene ontology and interaction modules occurs in melanoma cells with acquired BRAFi resistant in vitro (32). To investigate our results in the context of this and other data-sets a meta-analysis of datasets including Girotti et al. and Old et al. (a measure of short-term BRAFi in melanoma) was completed Table S7 in Supplementary Material $(31,32)$. Several sites in cytoskeletal proteins [e.g., Nestin (S680/768), Cortactin (S405) MAPB1 (S1793)] were commonly regulated in both our and the Girotti et al. (32) datasets. Less overlap is observed with the Old et al. screen, with only Cortactin (S405/S401) and NES (S768) regulated in all three data-sets. Additionally, we compared our data to an shRNA screen by Sun et al. for factors that influence the expression of EGFR in acquired drug resistance (13). Both SOX-10 and MTA2 were identified in the screen and both are measured in our proteomic data. We observed no change in SOX-10 protein expression, but an increase in MTA2 expression in drug resistance cells (Figure S1 in Supplementary Material).

\section{Drug Resistant Cells are Sensitive to CK2 Co-Inhibition}

Based on the measured increase in phosphorylation of several putative CK2 sites in LM-MEL-28R and our previous finding that CK2 inhibition is synergistic with BRAF inhibition in $B R A F(V 600 E)$ mutated cells (43), we tested whether LM-MEL28R was sensitive to CK2 inhibition. Figure 4 demonstrates that the resistant line was sensitive to co-inhibition with CK2 inhibitor CX-4595 and that this inhibition was beyond what was observed for CK2 alone in the drug sensitive LM-MEL-28. A quantitative reduction in cell growth over several concentrations of inhibitor ( $<50 \%$ at $2.5 \mu \mathrm{M}$ and $<90 \%$ at $5 \mu \mathrm{M})$ was observed in LM-MEL-28R.

\section{Discussion}

Changes in the phosphoproteome of a $B R A F(V 600 E)$ mutant melanoma cell line that occur after the development of drug (PLX4720) resistance in vitro are described here. Using a single step phosphopeptide enrichment followed by LC-MS analysis and label-free quantitation using the freeware Maxquant, we accurately detected and measured $\sim 2700$ phosphorylation events and 3556 proteins. Initially, we quantitated the viability of both unexposed and drug resistant populations in the presence of BRAFi. We observed that although viability was reduced after drug adaption, stable growth was maintained and cells were able to propagate in the presence of $5 \mu \mathrm{M}$ PLX 4720. Our in vitro system provided a suitable model to measure phosphorylation in drug resistance in vitro; and through kinases landscape analysis the activity of several kinases regulating these events was predicted.

Drug resistance in melanoma often occurs through reactivation of MAPK signaling despite continued exposure to the inhibitor (10). Through selective analysis of regulatory P-sites in the MAPK1 signaling pathway (ERK1/2) and downstream cell cycle regulators (RB1 and CDK1), our cell model was consistent with MAPK reactivation in resistant cells despite exposure to BRAFi. With this data set, we next investigated the relationship between protein phosphorylation and protein abundance. A measure for protein abundance was available for $\sim 72 \%$ of measured P-sites. The measure for protein was based upon all identified unmodified peptides mapping to the same protein group as the Psite-derived peptide spectral match. This measure could account for the dominant effects of protein metabolism (synthesis and degradation) often observed in cells during long-term adaptive responses. As expected, the abundance of the majority of P-sites closely followed that of protein expression, with only a small subset (46 P-sites) exhibiting changes in abundance that could not be accounted for by changes in the rate of protein turnover. The most likely explanation for this divergence is the activity of kinase(s) or phosphatase(s) with specific regulatory functions in cellular adaption to BRAF inhibition. Focusing on kinases where the most probable enzyme-substrate relationship(s) can be mapped, potential regulatory mechanisms were identified and are discussed below and summarized in Figure 5. 
A
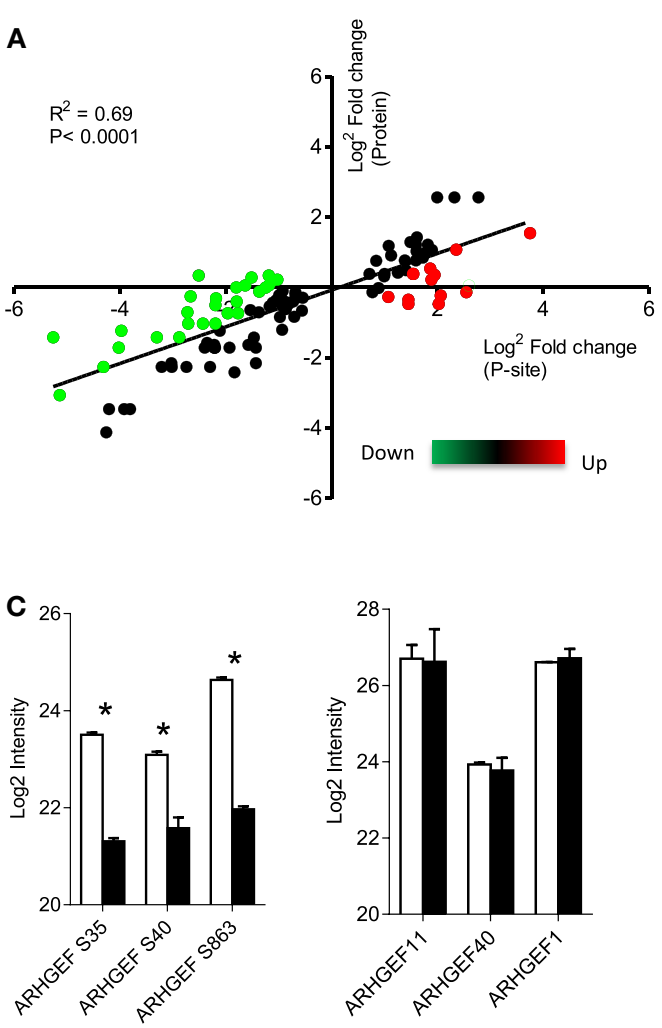

FIGURE 3 | Phosphorylation rate analysis. (A) Correlation of metrics for P-site effect with protein abundance effect measured between drug sensitive and resistant cell populations. Green $=$ P-site effect twofold $>$ protein effect. Red $=$ P-site effect twofold $<$ protein effect. Log $_{2}$
B

$$
{ }^{*} \mathrm{P}<.05, \mathrm{FDR}<.05
$$
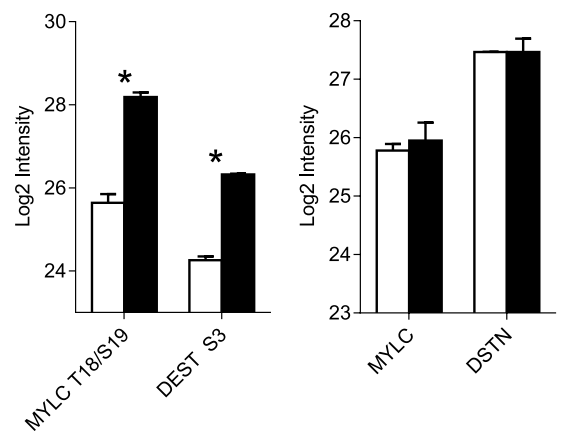

D
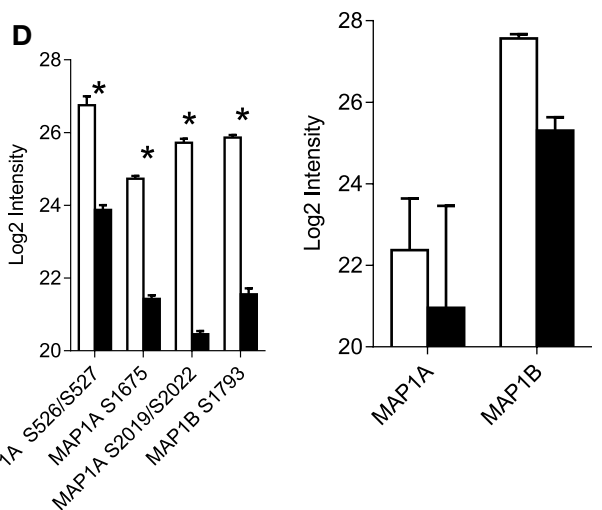

LM-MEL-28 intensity of P-sites and total protein for key cytoskeletal regulators

(B) myosin and destrin, (C) guanidine exchange factors (11, 40, and 1), and (D) microtubule-associated proteins $1 \mathrm{~A}$ and $1 \mathrm{~B}$ analyzed using a Student's t-test (error bars are SD).

\section{Drug Resistance Induces De/Phosphorylation of the Cytoskeleton Regulators}

Cytoskeletal changes are central to the phenotypic transitions that occur in tumor progression, altering invasiveness, metastasis, and resistance to therapy and this was reflected in our data. Psites that are key regulatory residues in proteins controlling both actin and microtubule-based filaments were altered beyond protein metabolic control. Destrin (actin-depolymerization factor, $\mathrm{ADF}$ ) is responsible for actin stability (44) and Ser-3 can be phosphorylated by LIM domain kinase 1 and 2 (LIMK1/2) to induce cytoskeletal reorganization to form stress fibers, membrane blebs and alter cell adhesion through the formation of Factin in non-muscle tissue $(45,46)$. Myosin light chain $(12 \mathrm{~A} / \mathrm{B} / 9)$ phosphorylation of S19 and T18 provide evidence for increased activity of several up-stream kinases [myosin light chain kinase (MLCK), Rho-associated kinase (ROCK), citron kinase, leucine zipper interacting kinase ZIPK/DAPK3, and CDC42 binding kinase]. Functionally, phosphorylation of S19/T18 alleviates autoinhibition of the MYLC globular heads and promotes interaction with actin to form bipolar filaments (47). The activating signals for this are diverse, ROCK2 is activated by the small GTP-binding protein RhoA, which is dependent on the activity of GEFs (48, 49). In the resistant cell population, a drop in phosphorylation of three different GEF's, including S35 in GEF11 was measured. Phosphorylation of GEF11 by the Cdc42 effector kinase PAK4 and p38 MAPK both lead to a drop in GEF activity $(50,51)$. Kinase enrichment analysis predicted a C-terminal site S35 to be a target for PAK4, indicating a novel site where PAK4 may regulate GEF activity in drug resistant cells. In the microtubule-based cytoskeleton, reduced phosphorylation of MAPs indicated altered tubule stabilization and several sites near microtubule binding domains could influence the tethering of cargo for transportation (52). Psite S1793 and S1797 in MAP2A are putative sites for GSK3- $\beta$. GSK3- $\beta$ activity couples extra-cellular matrix (ECM) signaling to the actin/microtubule cytoskeleton during cell migration (53).

The regulation of cytoskeletal dynamics by Rho/ROCK and GEF signaling is a key driver of the phenotypic transitions or switching that can change the migratory phenotype of cells (54). In melanoma, transcriptional networks that have roles in mesenchymal and amoeboid transitions alter during metastasis and response to therapy (55). These changes may contribute to the intrinsic invasive phenotypes that have been observed in response 
TABLE 2 | Regulated phosphosites in drug resistant cells and the prediction of putative regulatory kinases

\begin{tabular}{|c|c|c|c|c|c|c|}
\hline Protein names & Gene names & P-site & Diff $^{a}$ & $\boldsymbol{R}$ & PhosphoSitePlus kinase & NetworkIN \\
\hline $\begin{array}{l}\text { Serine/threonine-protein phosphatase } 2 \text { A regulatory } \\
\text { subunit B" subunit alpha }\end{array}$ & PPP2R3A & S692 & 1.41 & & & $\begin{array}{l}\text { MAPK3, MAPK1, } \\
\text { CDK1 }\end{array}$ \\
\hline Myosin regulatory light chain 12B & MYL12B & S25 & 2.74 & + & $\begin{array}{l}\text { ILK; DLK; DAPK1; ROCK1; AurB; } \\
\text { smMLCK; DAPK3; CAMK1A; CRIK; } \\
\text { MRCKA; PKCA; PAK1 }\end{array}$ & \\
\hline G-protein coupled receptor 143 & GPR143 & S343 & 1.28 & & & \\
\hline Destrin & DSTN & S3 & 2.29 & + & LIMK2; LIMK1; TESK1 & \\
\hline $40 S$ ribosomal protein S6 & RPS6 & S236 & 2.49 & + & PKCD; p90RSK; p70S6K; RSK2 & p70s6K \\
\hline Nucleoprotein TPR & TPR & S2155 & 1.59 & & & MAPK1 \\
\hline Choline-phosphate cytidylyltransferase A & PCYT1A & S347 & 1.66 & & & \\
\hline DNA replication licensing factor $\mathrm{MCM} 3$ & MCM3 & S717 & 1.15 & & & CK2alpha \\
\hline $60 S$ acidic ribosomal protein $\mathrm{P} 1$ & RPLP1 & S104 & 1.92 & & & CK2alpha \\
\hline 60S acidic ribosomal protein P2 & RPLP2 & S105 & 1.80 & & & GRK2, CK2alpha \\
\hline Insulin receptor substrate 2 & IRS2 & S736 & 1.34 & & & $\begin{array}{l}\text { GSK3alpha, } \\
\text { GSK3beta }\end{array}$ \\
\hline Choline-phosphate cytidylyltransferase A & PCYT1A & S331 & -1.25 & & & \\
\hline ATP-dependent RNA helicase DDX24 & DDX24 & S82 & -1.31 & & Chk1 & \\
\hline Ras-related GTP-binding protein C & RRAGC & S95 & -1.25 & & & \\
\hline Ankyrin repeat and SAM domain-containing protein $1 \mathrm{~A}$ & ANKS1A & S663 & -1.53 & & & \\
\hline Septin-9 & SEPTO9 & S85 & -1.24 & & & CK1delta \\
\hline CLIP-associating protein 1 & CLASP1 & S415 & -1.75 & & & NEK2, CaMKIlalpha \\
\hline Niban-like protein 1 & FAM129B & S641 & -1.23 & & & \\
\hline Sequestosome-1 & SQSTM1 & T269 & -1.62 & + & CDK1 & MAPK3 \\
\hline Syntaxin-12 & STX12 & S142 & -1.87 & & & \\
\hline E3 ubiquitin-protein ligase & NEDD4L & S308 & -1.06 & & & PDHK1, GSK3beta \\
\hline Rho guanine nucleotide exchange factor 11 & ARHGEF11 & S35 & -1.70 & & & PAK4 \\
\hline E3 ubiquitin-protein ligase & NEDD4L & S307 & -1.30 & + & PKACA; SGK1 & TGFbR2 \\
\hline Rho guanine nucleotide exchange factor 1 & ARHGEF1 & S919 & -2.42 & & & \\
\hline Microtubule-associated protein $1 \mathrm{~A}$ & MAP1A & S764 & -1.46 & & & \\
\hline Microtubule-associated protein $1 \mathrm{~A}$ & MAP1A & S765 & -1.46 & & & \\
\hline Microtubule-associated protein $1 \mathrm{~A}$ & MAP1A & S1913 & -1.89 & & & \\
\hline Cation-independent mannose-6-phosphate receptor & IGF2R & S2484 & -2.74 & & CK2A1 & CK2alpha \\
\hline Nestin & NES & S680 & -2.31 & & & CDK1, CDK5 \\
\hline Microtubule-associated protein 1B & MAP1B & S1793 & -2.05 & & & GSK3beta \\
\hline Microtubule-associated protein 1B & MAP1B & S1797 & -2.05 & & & GSK3beta \\
\hline PDZ and LIM domain protein 4 & PDLIM4 & S112 & -2.08 & & & \\
\hline Microtubule-associated protein $1 \mathrm{~A}$ & MAP1A & S2257 & -3.85 & & & CK1alpha, CK1delta \\
\hline Microtubule-associated protein $1 \mathrm{~A}$ & MAP1A & S2260 & -3.85 & & & CK1alpha, CK1delta \\
\hline
\end{tabular}

${ }^{a} \log _{2}$ fold change corrected for protein effect (see text), $R$ (known regulatory site). 


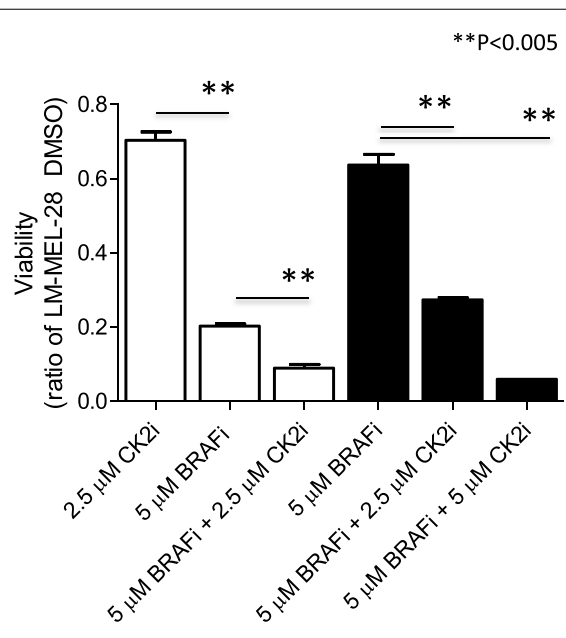

LM-MEL-28

LM-MEL-28 R

FIGURE 4 | CK2i of the drug resistant cell line (LM-MEL-28-R1). The effects of co-inhibition with the CK2 inhibitor CX-4945 and BRAFi (PLX4072) on proliferation of the drug resistant cell population LM-MEL-28-R1 were quantitated by viability assay, analyzed using a Student's $t$-test (error bars are $\mathrm{SD})$.

to inhibitor therapy $(25,32)$. ROCK1 and 2 promote myosin phosphorylation and actin fiber formation to drive amoeboid movement, where cell membranes undergo extensive blebbing allowing cells to deform and pass through voids in the surrounding matrix (56). Co-inhibition of ROCK signaling has recently been shown to enhance the anti-proliferative effect of the BRAFi PLX4720 and supports our observation that drug resistant populations utilize ROCK signaling as a pro-survival mechanism (57). Through a meta-analysis of our results with other drugexposed cell models $(31,32)$, a clear functional role can now be confirmed for the phosphorylation of proteins that function in the cytoskeleton. However, this analysis revealed that only 20/145 P-sites were shared between our data and that of Girotti et al. (32). This discrepancy could be explained by the myriad of possible mechanisms that can mediate drug resistance and is likely to depend on tumor genotype, heterogeneity, and locale; where each generates a unique cytoskeletal organization of maximum fitness. Outside of biological variation, technical differences in data generation and analysis may underlie the inconsistency in the P-sites identified. However, in Girotti et al., despite differences in methodology and only a twofold cut-off being applied to assign significance, of the sites that do overlap the majority of P-sites (13) exhibit a similar direction of regulation. While carrying out this meta-analysis, we also compared the proteomic data to the results of an shRNA screen for mechanisms of EGFR-based drug resistance in melanoma. Here, we identified MTA2 but not SOX10 protein expression as altered in drug resistant cells. In Sun et al. (13), MTA2 is ruled out as a false-positive mediator by a targeted approach. These data provide an indication that LMMEL-28, does not acquire BRAFi resistant through expression of EGFR receptor via SOX-10 attenuation; and could further explain the discrepancy in regulated P-sites with Girotti et al., where EGFR signaling is required for growth of the resistant cell population (32).

\section{Melanosome Signaling Through G-Protein Couple Receptor-143 (OA1)}

G-protein-coupled receptors can generate signals key to the development of resistance to BRAF inhibitor therapy (58). Here, we identified novel sites of phosphorylation (S331/S343) in the GPCR 143, also known as ocular albinism type 1 (GPR143/OA1), that increased in BRAFi resistant cells (Table 1; Figure 5). OA1 is a pigment-cell specific G-protein receptor for tyrosine, L-DOPA, and dopamine it also localizes to intracellular melanosomes and forms a key component of melanosome biogenesis and transport (59-61). OA1 regulates expression of the MITF, sustaining its expression and promoting melanocyte differentiation (62). Oncogenic BRAF can suppress MITF expression preventing normal melanocyte differentiation and promoting transformation to a de-differentiated proliferative state (63). In GPR143/OA1, S331/S343 reside in the C-terminal cytoplasmic domain and while no kinase prediction was assigned, phosphorylation here could drive the classical recruitment of beta-arrestins and lead to inactivation of G-protein signaling by OA1 leading to further dedifferentiation observed in drug resistant tumors (64). OA1 also signals through the actin/microtubule cytoskeleton to regulate the transport of melanosomes from the perinuclear region to the cell periphery and could in-part drive phosphorylation dynamics of the cytoskeleton indicated above (59). Finally, S331 is directly adjacent to a two amino acid "WE" domain vital for the correct localization of OA1 protein to the melanosome (65). Mutation of $\mathrm{WE}>\mathrm{AA}$ redirects $\mathrm{OA} 1$ to the plasma membrane (65). The role of OA1 phosphorylation in protein localization, melanosome and cytoskeleton signaling and how this facilitates drug resistance remain to be tested.

\section{Key P-Sites in Known Signaling Nodes Reflect MAPK1 Reactivation}

T497 in protein kinase $\mathrm{C}$ alpha (PKC $\alpha$ ) increased in expression and phosphorylation in drug resistant cells. T497 in PKC $\alpha$ is located in the activation loop and phosphorylation is essential for full catalytic activity of PKC $\alpha$ (66). Phosphorylation of T497 by PDPK1 (PDK1) is classically dependent on phosphatidylinositol metabolism and PI3K activation induced by GPCR or TRK signaling (Figure 5). PKC $\alpha$ activity in melanoma is highly context dependent with roles in both oncogenesis and growth suppression (67). PKC $\alpha$ can contribute to activation of the MAPK pathway through direct phosphorylation of RAF substrates to activate ERK, or promote the c-Jun N-terminal kinase (JNK) MAP kinase pathway through association with RACK1 $(68,69)$. RACK1 shuttles PKC $\alpha$ to target the stress-related MAPK JNK for phosphorylation leading to constitutive activation of p38 MAPK signaling (69). Interestingly, we measured dephosphorylation of S730/733 in SPAG9 (JIP4), a scaffold protein involved in the spatial organization of MAP kinases and a mediator of c-Jun $\mathrm{N}$-terminal kinase. The meta-analysis of Girotti et al. (32) supported this finding and while kinases/phosphatases able to regulate SPAG9 S730/733 phosphorylation remain unreported our data indicates that regulation may be key to the rewiring of MAPK 


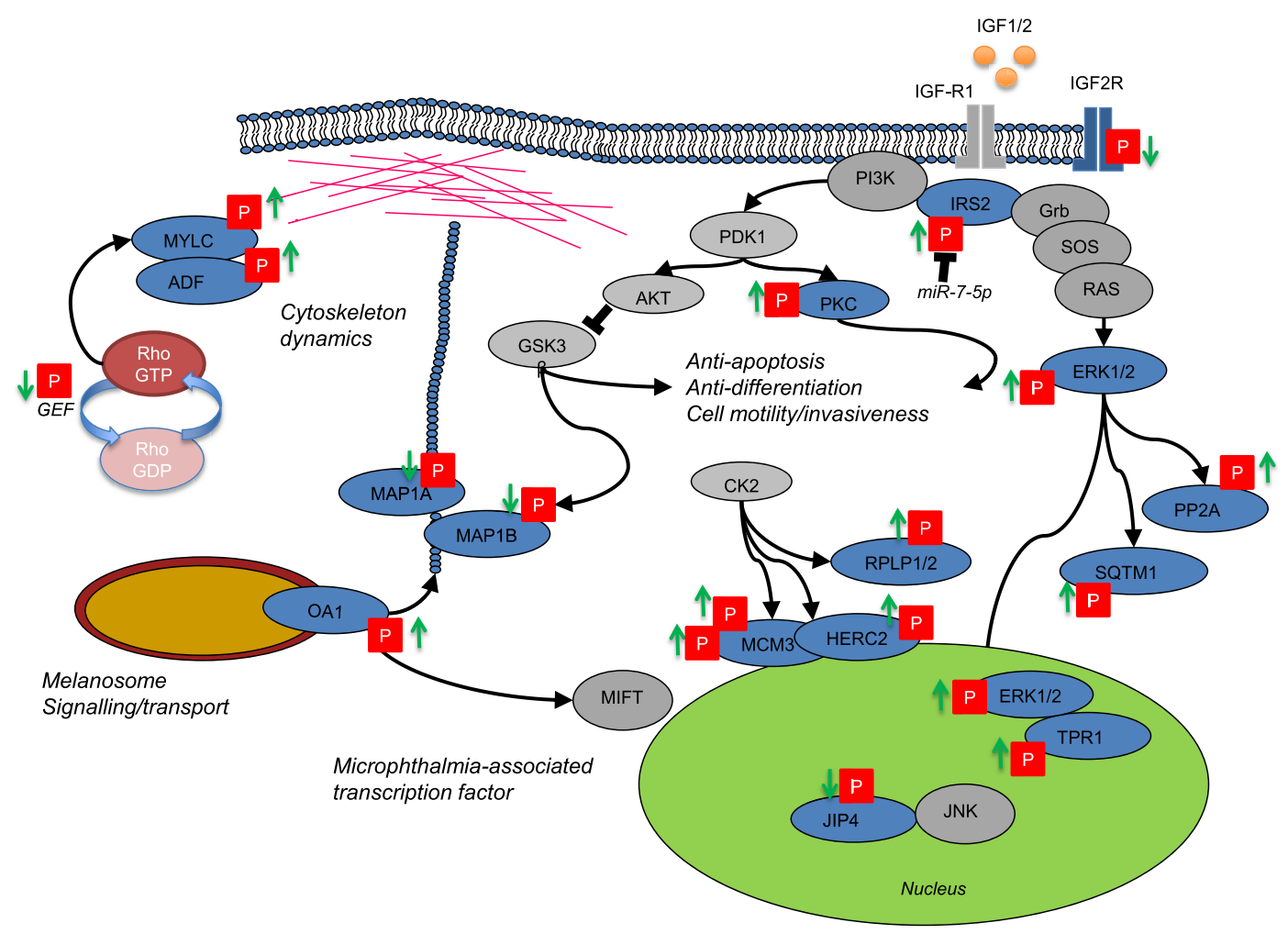

FIGURE 5 | Network cartoon summarizing the prominent differences in phosphorylation measured between BRAFi sensitive and resistant cell populations

signaling in cells adapted to BRAFi. A further mechanism able to reactivate ERK1/2 signaling in BRAFi resistance was indicated by the increased phosphorylation of the ERK/1/2 substrate TPR at S2155 (Table 1). TPR is a nuclear pore complex protein and chromatin regulator that in response to ERK1/2 phosphorylation can bind and localize ERK1/2 to chromatin (70). During shortterm exposure to BRAF and MEK inhibitors phosphorylation of TPR at S2155 reduces in BRAF(V600E) mutant cell lines (43). The recovery of TPR phosphorylation in the face of chronic BRAFi appears to be associated with the re-establishment of MAPK nuclear signaling in drug adapted cells.

Evidence for potential upstream mechanisms for ERK reactivation is provided by a change in phosphorylation of insulin receptor substrate (IRS2), a downstream effector of insulin-like growth factor receptor 1 (IGF-1R). IGF-1R signaling in cancer cells results from up-regulation of the receptor or its ligands (IGF-I and IGF-II) and contributes to the emergence of chemotherapeutic resistance. Insulin receptor substrate (IRS1/2) proteins transmit oncogenic signals through PI3K and ERK signaling modules (Figure 5). IRS1/2 also mediate the termination of IGF-IR signaling and resistance to PI3K inhibitors occurs through a reduction in this feedback inhibition [reviewed in Ref. (71)]. We measured phosphorylation of IRS2 at two sites, (i) S736 confidently localized and predicted to be regulated by GSK-3 $\alpha / \beta$ and (ii) an ambiguous P-site (either S730/731/735/740 or Y742) in the same peptide. A lack of clarity for the position of the second site makes it difficult to predict, which kinase(s) may be responsible for the regulation that we observed. However, phosphorylation of IRS2 represents a key signaling process where cells become reprogramed through $\mathrm{PI} 3 \mathrm{~K}$ to activate PDK1-PKC/PKB(AKT) or through GRB2-SOS to activate the Ras-MAPK pathway directly (Figure 5) (72). IGF-1R has been shown to be up-regulated in drug resistant melanoma cell lines previously (12). Recently, IRS2 was also found up-regulated in BRAFi (PLX4032) resistant tumors and blocking or eliminating IRS or subsequent PI3K-mediated signaling may provide therapeutic potential $(12,73)$. More specifically, IRS-2 is a target of miR-7-5p found down-regulated in melanoma (74). miR-7-5p down-regulation is associated with increased cell migration and metastasis, and using RNA interference (RNAi) IRS-2 was shown to regulate this phenotype through the $\mathrm{PKB} / \mathrm{AKT}$ signaling node $(74,75)$. In support of a role for IGF signaling, a decrease in the phosphorylation of a CK2 site (S2484) in the cytoplasmic domain of the insulin-like growth factor receptor II (IGFR2) known also as the CI-MPR receptor was detected in BRAFi drug resistant cells. This protein acts as both the receptor for IGF2 and mannose-6phosphate and is implicated in both G-protein signaling and the targeting of lysosomal enzymes. In CHO cells, phosphorylation of this site regulates changes in the trafficking of the receptor in the Golgi-network (76) and down-regulation of plasma membrane IGFR2 is associated with increased signaling through IGF-R1 (77).

This study demonstrated a simple and effective approach to detect kinase activity important in the transition of cells from a BRAF sensitive to BRAF resistant phenotype. Once detected these kinase present themselves as potential targets for future 
co-therapies. During our analysis, we detected increases in the phosphorylation and abundance of proteins involved in processes related to DNA metabolism. Several of these sites were substrates for CK2A, and we tested if long-term exposure to BRAFi provided protection from the synergistic inhibitory effects of protein kinase CK2A-BRAF co-inhibition previously observed in BRAF(V600E) mutant melanoma (43). This was not the case with an additive effect $(>50 \%$ ) being observed in both parental and resistant populations, suggesting that this drug combination could be effective in reducing the emergence of resistant cell populations. We have previously demonstrated that CK2 plays an important role in priming the activity of Akt through phosphorylation at S129, and that controlling CK2 activity is an effective strategy in preventing cell growth in BRAF melanoma and BRAF thyroid carcinoma (43). Notwithstanding the importance of Akt-driven growth pathway, CK2 is a ubiquitous serine/threonine kinase and in the nucleus plays an important role in modulating DNA-damage and repair machinery $(78,79)$; it is likely that the inhibitory effect of blocking CK2 leads to wide-spread modulation in numerous other pathways that support cell proliferation. Understanding the mechanistic significance of how CK2 regulates these other pathways in melanoma needs ongoing research.

\section{Conclusion}

A central paradigm of acquired drug resistance in BRAF mutant melanomas is the reactivation of MAPK signaling (10). In this work, a quantitative MS method measuring both the phosphoproteome and proteome was developed and implemented to describe novel phosphorylation-based signaling events in cells after this transition in vitro. We identified increased MAPK01 phosphorylation alongside well-known and novel protein phosphorylation events driven by this and other kinases. Regulation of key substrates in Rho/ROCK signaling axis provided evidence for cytoskeletal rearrangements able to facilitate a phenotypic switch in cell motility that evolve during BRAFi therapy. Importantly,

\section{References}

1. Omholt K, Platz A, Kanter L, Ringborg U, Hansson J. NRAS and BRAF mutations arise early during melanoma pathogenesis and are preserved throughout tumor progression. Clin Cancer Res (2003) 9:6483-8.

2. Long GV, Menzies AM, Nagrial AM, Haydu LE, Hamilton AL, Mann GJ, et al. Prognostic and clinicopathologic associations of oncogenic BRAF in metastatic melanoma. J Clin Oncol (2011) 29:1239-46. doi:10.1200/JCO.2010.32.4327

3. Jakob JA, Bassett RL Jr, Ng CS, Curry JL, Joseph RW, Alvarado GC, et al. NRAS mutation status is an independent prognostic factor in metastatic melanoma. Cancer (2012) 118:4014-23. doi:10.1002/cncr.26724

4. Joseph EW, Pratilas CA, Poulikakos PI, Tadi M, Wang W, Taylor BS, et al. The RAF inhibitor PLX4032 inhibits ERK signaling and tumor cell proliferation in a V600E BRAF-selective manner. Proc Natl Acad Sci U S A (2010) 107:14903-8. doi:10.1073/pnas.1008990107

5. Chapman PB, Hauschild A, Robert C, Haanen JB, Ascierto P, Larkin J, et al. Improved survival with vemurafenib in melanoma with BRAF V600E mutation. N Engl J Med (2011) 364:2507-16. doi:10.1056/NEJMoa1103782

6. Flaherty KT, Puzanov I, Kim KB, Ribas A, McArthur GA, Sosman JA, et al. Inhibition of mutated, activated BRAF in metastatic melanoma. $N$ Engl J Med (2010) 363:809-19. doi:10.1056/NEJMoa1002011

7. Sullivan RJ, Flaherty K. MAP kinase signaling and inhibition in melanoma. Oncogene (2013) 32:2373-9. doi:10.1038/onc.2012.345 our study provided evidence for signaling events in several proteins (IGFR2, IRS1, PKC, and GEFs) associated with established pathways of drug resistance in melanoma and other cancers (12, 80). Phosphorylation of IRS1 re-enforces the importance of IGF signaling in drug resistant melanoma as a valid target for cotherapy. Novel sites identified indicate new and untested mechanisms able to promote cell survival and these require confirmation in vivo. The diversity of drug resistance mechanisms discovered in melanoma so far indicates a need to develop an individualized approach to multi-targeted cancer treatment. The MS-driven phosphoproteomic method described here can be readily applied to the analysis of tumors biopsied before, during, and after treatment to provide a direct readout for kinases that are drug-able targets in relapsed patients.

\section{Acknowledgments}

The authors would like to acknowledge Ann Parker for proof reading and aiding efficient communication of this work. This work was supported, in part, by funds from the Operational Infrastructure Support Program provided by the Victorian State Government and through access to the Australia Proteome Analysis Facility supported by the Australian Government's National Collaborative Research Infrastructure Scheme. MM acknowledges support from Cancer Institute NSW through Sydney VITAL translational cancer research center. Financial support: MM acknowledges support by Macquarie University and Cancer Institute NSW. Aspects of this research were conducted at APAF established under the Australian Government's National Collaborative Research Infrastructure Scheme.

\section{Supplementary Material}

The Supplementary Material for this article can be found online at http://journal.frontiersin.org/article/10.3389/fonc.2015.00095

8. Sullivan RJ, Flaherty KT. Resistance to BRAF-targeted therapy in melanoma Eur J Cancer (2013) 49:1297-304. doi:10.1016/j.ejca.2012.11.019

9. Pritchard AL, Hayward NK. Molecular pathways: mitogen-activated protein kinase pathway mutations and drug resistance. Clin Cancer Res (2013) 19:2301-9. doi:10.1158/1078-0432.CCR-12-0383

10. Tap WD, Gong KW, Dering J, Tseng Y, Ginther C, Pauletti G, et al. Pharmacodynamic characterization of the efficacy signals due to selective BRAF inhibition with PLX4032 in malignant melanoma. Neoplasia (2010) 12: 637-49. doi:10.1593/neo.10414

11. Yadav V, Zhang X, Liu J, Estrem S, Li S, Gong XQ, et al. Reactivation of mitogenactivated protein kinase (MAPK) pathway by FGF receptor 3 (FGFR3)/Ras mediates resistance to vemurafenib in human B-RAF V600E mutant melanoma. J Biol Chem (2012) 287:28087-98. doi:10.1074/jbc.M112.377218

12. Villanueva J, Vultur A, Lee JT, Somasundaram R, Fukunaga-Kalabis M, Cipolla $\mathrm{AK}$, et al. Acquired resistance to BRAF inhibitors mediated by a RAF kinase switch in melanoma can be overcome by cotargeting MEK and IGF-1R/PI3K. Cancer Cell (2010) 18:683-95. doi:10.1016/j.ccr.2010.11.023

13. Sun C, Wang L, Huang S, Heynen GJ, Prahallad A, Robert C, et al. Reversible and adaptive resistance to BRAF(V600E) inhibition in melanoma. Nature (2014) 508:118-22. doi:10.1038/nature13121

14. Poulikakos PI, Zhang C, Bollag G, Shokat KM, Rosen N. RAF inhibitors transactivate RAF dimers and ERK signalling in cells with wild-type BRAF Nature (2010) 464:427-30. doi:10.1038/nature08902 
15. Hatzivassiliou G, Song K, Yen I, Brandhuber BJ, Anderson DJ, Alvarado R, et al. RAF inhibitors prime wild-type RAF to activate the MAPK pathway and enhance growth. Nature (2010) 464:431-5. doi:10.1038/nature08833

16. Mooz J, Oberoi-Khanuja TK, Harms GS, Wang W, Jaiswal BS, Seshagiri S, et al. Dimerization of the kinase ARAF promotes MAPK pathway activation and cell migration. Sci Signal (2014) 7:ra73. doi:10.1126/scisignal.2005484

17. Heidorn SJ, Milagre C, Whittaker S, Nourry A, Niculescu-Duvas I, Dhomen $\mathrm{N}$, et al. Kinase-dead BRAF and oncogenic RAS cooperate to drive tumor progression through CRAF. Cell (2010) 140:209-21. doi:10.1016/j.cell.2009.12. 040

18. Johannessen CM, Boehm JS, Kim SY, Thomas SR, Wardwell L, Johnson LA, et al. COT drives resistance to RAF inhibition through MAP kinase pathway reactivation. Nature (2010) 468:968-72. doi:10.1038/nature09627

19. Emery CM, Vijayendran KG, Zipser MC, Sawyer AM, Niu L, Kim JJ, et al. MEK1 mutations confer resistance to MEK and B-RAF inhibition. Proc Natl Acad Sci U S A (2009) 106:20411-6. doi:10.1073/pnas.0905833106

20. Poulikakos PI, Persaud Y, Janakiraman M, Kong X, Ng C, Moriceau G, et al. RAF inhibitor resistance is mediated by dimerization of aberrantly spliced BRAF(V600E). Nature (2011) 480:387-90. doi:10.1038/nature10662

21. Kemper K, de Goeje PL, Peeper DS, van Amerongen R. Phenotype switching: tumor cell plasticity as a resistance mechanism and target for therapy. Cancer Res (2014) 74:5937-41. doi:10.1158/0008-5472.CAN-14-1174

22. Straussman R, Morikawa T, Shee K, Barzily-Rokni M, Qian ZR, Du J, et al. Tumour micro-environment elicits innate resistance to RAF inhibitors through HGF secretion. Nature (2012) 487:500-4. doi:10.1038/nature11183

23. Konieczkowski DJ, Johannessen CM, Abudayyeh O, Kim JW, Cooper ZA, Piris A, et al. A melanoma cell state distinction influences sensitivity to MAPK pathway inhibitors. Cancer Discov (2014) 4:816-27. doi:10.1158/2159-8290. CD-13-0424

24. Hoek KS, Schlegel NC, Brafford P, Sucker A, Ugurel S, Kumar R, et al. Metastatic potential of melanomas defined by specific gene expression profiles with no BRAF signature. Pigment Cell Res (2006) 19:290-302. doi:10.1111/j.1600-0749. 2006.00322.x

25. Zipser MC, Eichhoff OM, Widmer DS, Schlegel NC, Schoenewolf NL, Stuart $\mathrm{D}$, et al. A proliferative melanoma cell phenotype is responsive to RAF/MEK inhibition independent of BRAF mutation status. Pigment Cell Melanoma Res (2011) 24:326-33. doi:10.1111/j.1755-148X.2010.00823.x

26. Atefi $\mathrm{M}$, von Euw E, Attar $\mathrm{N}, \mathrm{Ng} \mathrm{C}$, Chu C, Guo D, et al. Reversing melanoma cross-resistance to BRAF and MEK inhibitors by co-targeting the AKT/mTOR pathway. PLoS One (2011) 6:e28973. doi:10.1371/journal.pone. 0028973

27. Greger JG, Eastman SD, Zhang V, Bleam MR, Hughes AM, Smitheman KN, et al. Combinations of BRAF, MEK, and PI3K/mTOR inhibitors overcome acquired resistance to the BRAF inhibitor GSK2118436 dabrafenib, mediated by NRAS or MEK mutations. Mol Cancer Ther (2012) 11:909-20. doi:10.1158/ 1535-7163.MCT-11-0989

28. Roux PP, Thibault P. The coming of age of phosphoproteomics - from large data sets to inference of protein functions. Mol Cell Proteomics (2013) 12:3453-64. doi:10.1074/mcp.R113.032862

29. Wilkes EH, Casado P, Cutillas PR. Approaches for measuring signalling plasticity in the context of resistance to targeted cancer therapies. Biochem Soc Trans (2014) 42:791-7. doi:10.1042/BST20140029

30. Alcolea MP, Casado P, Rodriguez-Prados JC, Vanhaesebroeck B, Cutillas PR. Phosphoproteomic analysis of leukemia cells under basal and drug-treated conditions identifies markers of kinase pathway activation and mechanisms of resistance. Mol Cell Proteomics (2012) 11:453-66. doi:10.1074/mcp.M112. 017483

31. Old WM, Shabb JB, Houel S, Wang H, Couts KL, Yen CY, et al. Functional proteomics identifies targets of phosphorylation by B-Raf signaling in melanoma. Mol Cell (2009) 34:115-31. doi:10.1016/j.molcel.2009.03.007

32. Girotti MR, Pedersen M, Sanchez-Laorden B, Viros A, Turajlic S, NiculescuDuvaz D, et al. Inhibiting EGF receptor or SRC family kinase signaling overcomes BRAF inhibitor resistance in melanoma. Cancer Discov (2013) 3:158-67. doi:10.1158/2159-8290.CD-12-0386

33. Behren A, Anaka M, Lo PH, Vella LJ, Davis ID, Catimel J, et al. The Ludwig institute for cancer research Melbourne melanoma cell line panel. Pigment Cell Melanoma Res (2013) 26:597-600.

34. Boersema PJ, Aye TT, van Veen TA, Heck AJ, Mohammed S. Triplex protein quantification based on stable isotope labeling by peptide dimethylation applied to cell and tissue lysates. Proteomics (2008) 8:4624-32. doi:10.1002/ pmic. 200800297

35. Parker R, Melathopoulos AP, White R, Pernal SF, Guarna MM, Foster LJ. Ecological adaptation of diverse honey bee (Apis mellifera) populations. PLoS One (2010) 5:e11096. doi:10.1371/journal.pone.0011096

36. Ishihama Y, Rappsilber J, Mann M. Modular stop and go extraction tips with stacked disks for parallel and multidimensional peptide fractionation in proteomics. J Proteome Res (2006) 5:988-94. doi:10.1021/ pr050385q

37. Wisniewski JR, Zougman A, Mann M. Combination of FASP and StageTipbased fractionation allows in-depth analysis of the hippocampal membrane proteome. J Proteome Res (2009) 8:5674-8. doi:10.1021/pr900748n

38. Cox J, Hein MY, Luber CA, Paron I, Nagaraj N, Mann M. Accurate proteomewide label-free quantification by delayed normalization and maximal peptide ratio extraction, termed MaxLFQ. Mol Cell Proteomics (2014) 13:2513-26. doi:10.1074/mcp.M113.031591

39. Cox J, Mann M. 1D and 2D annotation enrichment: a statistical method integrating quantitative proteomics with complementary high-throughput data. BMC Bioinformatics (2012) 13(Suppl 16):S12. doi:10.1186/1471-2105-13-S16-S12

40. Vizcaino JA, Deutsch EW, Wang R, Csordas A, Reisinger F, Rios D, et al. Hermjakob, ProteomeXchange provides globally coordinated proteomics data submission and dissemination. Nature Biotechnology (2014) 32: 223-6.

41. Linding R, Jensen LJ, Pasculescu A, Olhovsky M, Colwill K, Bork P, et al. NetworKIN: a resource for exploring cellular phosphorylation networks. Nucleic Acids Res (2008) 36:D695-9. doi:10.1093/nar/gkm902

42. Hornbeck PV, Kornhauser JM, Tkachev S, Zhang B, Skrzypek E, Murray B, et al. PhosphoSitePlus: a comprehensive resource for investigating the structure and function of experimentally determined post-translational modifications in man and mouse. Nucleic Acids Res (2012) 40:D261-70. doi:10.1093/nar/ gkr1122

43. Parker R, Clifton-Bligh R, Molloy MP. Phosphoproteomics of MAPK inhibition in BRAF-mutated cells and a role for the lethal synergism of dual BRAF and CK2 inhibition. Mol Cancer Ther (2014) 13:1894-906. doi:10.1158/1535-7163. MCT-13-0938

44. Bamburg JR, Bernstein BW. Roles of ADF/cofilin in actin polymerization and beyond. F1000 Biol Rep (2010) 2:62. doi:10.3410/B2-62

45. Yang N, Higuchi O, Ohashi K, Nagata K, Wada A, Kangawa K, et al. Cofilin phosphorylation by LIM-kinase 1 and its role in Rac-mediated actin reorganization. Nature (1998) 393:809-12. doi:10.1038/31735

46. Moriyama K, Iida K, Yahara I. Phosphorylation of Ser-3 of cofilin regulates its essential function on actin. Genes Cells (1996) 1:73-86. doi:10.1046/j. 1365-2443.1996.05005.x

47. Vicente-Manzanares M, Ma X, Adelstein RS, Horwitz AR. Non-muscle myosin II takes centre stage in cell adhesion and migration. Nat Rev Mol Cell Biol (2009) 10:778-90. doi:10.1038/nrm2786

48. Julian L, Olson MF. Rho-associated coiled-coil containing kinases (ROCK): structure, regulation, and functions. Small GTPases (2014) 5:e29846. doi:10. 4161/sgtp. 29846

49. Schmidt A, Hall A. Guanine nucleotide exchange factors for Rho GTPases: turning on the switch. Genes Dev (2002) 16:1587-609. doi:10.1101/gad. 1003302

50. Barac A, Basile J, Vazquez-Prado J, Gao Y, Zheng Y, Gutkind JS. Direct interaction of p21-activated kinase 4 with PDZ-RhoGEF, a G protein-linked Rho guanine exchange factor. J Biol Chem (2004) 279:6182-9. doi:10.1074/jbc. M309579200

51. Chikumi H, Barac A, Behbahani B, Gao Y, Teramoto H, Zheng Y, et al. Homo- and hetero-oligomerization of PDZ-RhoGEF, LARG and p115RhoGEF by their C-terminal region regulates their in vivo Rho GEF activity and transforming potential. Oncogene (2004) 23:233-40. doi:10.1038/sj.onc. 1207012

52. Hufnagel A, Elger CE, Boker DK, Linke DB, Kurthen M, Solymosi L. Activation of the epileptic focus during intracarotid amobarbital test. Electrocorticographic registration via subdural electrodes. Electroencephalogr Clin Neurophysiol (1990) 75:453-63. doi:10.1016/0013-4694(90)90132-4

53. Goold RG, Gordon-Weeks PR. Microtubule-associated protein 1B phosphorylation by glycogen synthase kinase 3 beta is induced during PC12 cell differentiation. J Cell Sci (2001) 114:4273-84. 
54. Pankova K, Rosel D, Novotny M, Brabek J. The molecular mechanisms of transition between mesenchymal and amoeboid invasiveness in tumor cells. Cell Mol Life Sci (2010) 67:63-71. doi:10.1007/s00018-009-0132-1

55. Vandamme N, Berx G. Melanoma cells revive an embryonic transcriptional network to dictate phenotypic heterogeneity. Front Oncol (2014) 4:352. doi:10. 3389/fonc.2014.00352

56. Wyckoff JB, Pinner SE, Gschmeissner S, Condeelis JS, Sahai E. ROCKand myosin-dependent matrix deformation enables protease-independent tumor-cell invasion in vivo. Curr Biol (2006) 16:1515-23. doi:10.1016/j.cub. 2006.05.065

57. Smit MA, Maddalo G, Greig K, Raaijmakers LM, Possik PA, van Breukelen $\mathrm{B}$, et al. ROCK1 is a potential combinatorial drug target for BRAF mutant melanoma. Mol Syst Biol (2014) 10:772. doi:10.15252/msb.20145450

58. Johannessen CM, Johnson LA, Piccioni F, Townes A, Frederick DT, Donahue $\mathrm{MK}$, et al. A melanocyte lineage program confers resistance to MAP kinase pathway inhibition. Nature (2013) 504:138-42. doi:10.1038/nature12688

59. Palmisano I, Bagnato P, Palmigiano A, Innamorati G, Rotondo G, Altimare D, et al. The ocular albinism type 1 protein, an intracellular $G$ protein-coupled receptor, regulates melanosome transport in pigment cells. Hum Mol Genet (2008) 17:3487-501. doi:10.1093/hmg/ddn241

60. Innamorati G, Piccirillo R, Bagnato P, Palmisano I, Schiaffino MV. The melanosomal/lysosomal protein OA1 has properties of a $\mathrm{G}$ protein-coupled receptor. Pigment Cell Res (2006) 19:125-35. doi:10.1111/j.1600-0749.2006. 00292.x

61. Giordano F, Bonetti C, Surace EM, Marigo V, Raposo G. The ocular albinism type 1 (OA1) G-protein-coupled receptor functions with MART-1 at early stages of melanogenesis to control melanosome identity and composition. Hum Mol Genet (2009) 18:4530-45. doi:10.1093/hmg/ddp415

62. Falletta P, Bagnato P, Bono M, Monticone M, Schiaffino MV, Bennett DC, et al. Melanosome-autonomous regulation of size and number: the OA1 receptor sustains PMEL expression. Pigment Cell Melanoma Res (2014) 27:565-79. doi:10.1111/pcmr.12239

63. Wellbrock C, Rana S, Paterson H, Pickersgill H, Brummelkamp T, Marais R. Oncogenic BRAF regulates melanoma proliferation through the lineage specific factor MITF. PLoS One (2008) 3:e2734. doi:10.1371/journal.pone.0002734

64. Zhang J, Ferguson SS, Barak LS, Aber MJ, Giros B, Lefkowitz RJ, et al. Molecular mechanisms of $G$ protein-coupled receptor signaling: role of $G$ protein-coupled receptor kinases and arrestins in receptor desensitization and resensitization. Receptors Channels (1997) 5:193-9.

65. Piccirillo R, Palmisano I, Innamorati G, Bagnato P, Altimare D, Schiaffino MV. An unconventional dileucine-based motif and a novel cytosolic motif are required for the lysosomal and melanosomal targeting of OA1. J Cell Sci (2006) 119:2003-14. doi:10.1242/jcs.02930

66. Nakashima S. Protein kinase $\mathrm{C}$ alpha (PKC alpha): regulation and biological function. J Biochem (2002) 132:669-75. doi:10.1093/oxfordjournals.jbchem. a003272

67. Denning MF. Specifying protein kinase C functions in melanoma. Pigment Cell Melanoma Res (2012) 25:466-76. doi:10.1111/j.1755-148X.2012.01015.x

68. Schonwasser DC, Marais RM, Marshall CJ, Parker PJ. Activation of the mitogen-activated protein kinase/extracellular signal-regulated kinase pathway by conventional, novel, and atypical protein kinase $\mathrm{C}$ isotypes. $\mathrm{Mol} \mathrm{Cell}$ Biol (1998) 18:790-8.
69. Lopez-Bergami P, Huang C, Goydos JS, Yip D, Bar-Eli M, Herlyn M, et al. Rewired ERK-JNK signaling pathways in melanoma. Cancer Cell (2007) 11:447-60. doi:10.1016/j.ccr.2007.03.009

70. Vomastek T, Iwanicki MP, Burack WR, Tiwari D, Kumar D, Parsons JT, et al. Extracellular signal-regulated kinase 2 (ERK2) phosphorylation sites and docking domain on the nuclear pore complex protein Tpr cooperatively regulate ERK2-Tpr interaction. Mol Cell Biol (2008) 28:6954-66. doi:10.1128/MCB. 00925-08

71. Bagrodia S, Smeal T, Abraham RT. Mechanisms of intrinsic and acquired resistance to kinase-targeted therapies. Pigment Cell Melanoma Res (2012) 25:819-31. doi:10.1111/pcmr.12007

72. Taniguchi CM, Emanuelli B, Kahn CR. Critical nodes in signalling pathways: insights into insulin action. Nat Rev Mol Cell Biol (2006) 7:85-96. doi:10.1038/ nrm 1837

73. Reuveni H, Flashner-Abramson E, Steiner L, Makedonski K, Song R, Shir A, et al. Therapeutic destruction of insulin receptor substrates for cancer treatment. Cancer Res (2013) 73:4383-94. doi:10.1158/0008-5472.CAN-12-3385

74. Giles KM, Brown RA, Epis MR, Kalinowski FC, Leedman PJ. miRNA-7-5p inhibits melanoma cell migration and invasion. Biochem Biophys Res Commun (2013) 430:706-10. doi:10.1016/j.bbrc.2012.11.086

75. Shaw LM. Identification of insulin receptor substrate 1 (IRS-1) and IRS-2 as signaling intermediates in the alpha6beta4 integrin-dependent activation of phosphoinositide 3-OH kinase and promotion of invasion. Mol Cell Biol (2001) 21:5082-93. doi:10.1128/MCB.21.15.5082-5093.2001

76. Meresse S, Hoflack B. Phosphorylation of the cation-independent mannose 6-phosphate receptor is closely associated with its exit from the trans-Golgi network. J Cell Biol (1993) 120:67-75. doi:10.1083/jcb.120.1.67

77. Osipo C, Dorman S, Frankfater A. Loss of insulin-like growth factor II receptor expression promotes growth in cancer by increasing intracellular signaling from both IGF-I and insulin receptors. Exp Cell Res (2001) 264:388-96. doi:10.1006/ excr.2000.5121

78. Becherel OJ, Jakob B, Cherry AL, Gueven N, Fusser M, Kijas AW, et al. CK2 phosphorylation-dependent interaction between aprataxin and MDC1 in the DNA damage response. Nucleic Acids Res (2010) 38:1489-503. doi:10.1093/nar/ gkp1149

79. Loizou JI, El-Khamisy SF, Zlatanou A, Moore DJ, Chan DW, Qin J, et al. The protein kinase CK2 facilitates repair of chromosomal DNA single-strand breaks. Cell (2004) 117:17-28. doi:10.1016/S0092-8674(04)00206-5

80. Silvy F, Lissitzky JC, Bruneau N, Zucchini N, Landrier JF, Lombardo D, et al. Resistance to cisplatin-induced cell death conferred by the activity of organic anion transporting polypeptides (OATP) in human melanoma cells. Pigment Cell Melanoma Res (2013) 26:592-6. doi:10.1111/pcmr.12108

Conflict of Interest Statement: The authors declare that the research was conducted in the absence of any commercial or financial relationships that could be construed as a potential conflict of interest.

Copyright (C) 2015 Parker,Vella, Xavier, Amirkhani, Parker, Cebon and Molloy. This is an open-access article distributed under the terms of the Creative Commons Attribution License (CC BY). The use, distribution or reproduction in other forums is permitted, provided the original author(s) or licensor are credited and that the original publication in this journal is cited, in accordance with accepted academic practice. No use, distribution or reproduction is permitted which does not comply with these terms. 